\title{
EL CAMBIO DEL LATÍN AL ROMANCE EN LA CANCILLERÍA REAL DE CASTILLA
}

\author{
ROBERT A. MACDONALD \\ Emeritus, University of Richmond \\ (USA)
}

\section{SUMARIO}

1.1. El movimiento hacia la vernacularización.- 1.2. Plan de investigación y fuentes.- 1.3. Tipología de documentos cancillerescos.- 2.1. Datando los primeros usos del romance en la cancillería castellana. Privilegios rodados.- 2.2. Otros privilegios y cartas.- 2.3. Otros documentos legislativos.- 2.4. Conclusión.- 3.1. Personal: cancilleres nominales o en funciones.- 3.2. Escribas en la cancillería.- 3.3. Personas interesadas en el cambio de lenguas.- 3.4. Conclusión.- 4.1. Motivos para sustituir el latín.- 4.2. La utilidad de la lengua vernácula.- 4.3. El uso creciente del romance en documentos reales y no reales.- 4.4. Comentario final.

\subsection{EL MOVIMIENTO HACIA LA VERNACULARIZACIÓN}

Fue en el siglo XIII cuando en Castilla y León el proceso de codificación de leyes, ya comenzado en algunas regiones europeas, fue acompañado por la adopción de la lengua vernácula en los códigos publicados $^{1}$. La vernacularización ocurría también en la historiografía y en

\footnotetext{
'Armin WOLF, El movimiento de legislación y de codificación en Europa en tiempos de Alfonso el Sabio, "Alfonso X el Sabio, Vida, Obra y Época", I (único publicado), Madrid, 1989, pp. 31-37. Wolf escribía sobre el asunto en artículos anteriores también.

"Anuario de Estudios Medievales", 27 (1997)
} 
la literatura ${ }^{2}$. En los dos reinos hispánicos algunos ejemplos ilustran la presencia de este movimiento en los campos referidos. Con respecto a la codificación, en lugar del latín que se había empleado en compilaciones forales y en el Liber Judicum se usaba el romance en nuevos fueros, en el Libro Juzgo y en los códigos atribuidos a Alfonso X. En cuanto a la historiografía, en lugar del latín de muchos anales o de las crónicas como $D e$ rebus Hispaniae de Jiménez de Rada se escribían las 'estorias' alfonsinas en romance. En la literatura, el latín de los escritos sapienciales, de la hagiografía y de las colecciones de milagros cedía el paso al romance en la poesía épica y lírica, en los relatos de aventuras y en las nuevas colecciones de milagros. El cambio en el uso de lenguas a veces indicaba además alteraciones en la forma ${ }^{3}$. En este artículo pienso apuntar el curso de la vernacularización de la itinerante cancillería castellana e identificar el personal responsable y las circunstancias con las que se relacionaba el cambio mencionado.

\subsection{PLAN DE INVESTIGACIÓN Y FUENTES}

Todos los documentos auténticos expedidos por las cancillerías de Alfonso VIII (1158-1214) y Enrique I (1214-1217) estaban en latín menos el único caso notado por Julio González ${ }^{4}$. Todos los expedidos por la

\footnotetext{
${ }^{2} \mathrm{Karl}$ D. UITTI, A Note on Historiographical Vernacularization in Thirteenth-Century France and Spain, "Homenaje a Alvaro Galmés de Fuentes" (2 vols., Oviedo, 1985), I, pp. 573-592, y Gabrielle M. SPIEGEL, Romancing the Past. The Rise of Vernacular Prose Historiography in Thirteenth-Century France, Berkeley, 1993. En el Prefacio a su libro Orígenes del español (Madrid, $6^{a}$ edición, 1968) Ramón MENÉNDEZ PIDAL nota la secularización de la cultura por toda Romania y el ascenso del romance a una posición superior a la del latín. Ernst $R$. CURTIUS, en el Apéndice (p. 592) a su European Literature and the Latin Middle Ages, New York, 1953, fija, en la Universidad de París, específicamente en 1215 el límite del estudio de las obras clásicas y su sustitución por la lógica formal, y aproximadamente en 1225 el fin del florecimiento espléndido de la poesía y literatura latinas.

${ }^{3} \mathrm{Cf}$. Francisco LÓPEZ ESTRADA, Introducción a la literatura medieval española, Madrid, $4^{a}$ edición, 1979, caps. IV-VII, especialmente pp. 48-51, 117-123, 148-150, 302-303 y 403-404.

${ }^{4} J u l i o$ GonZÁlEZ, El reino de Castilla en la época de Alfonso VIII (3 vols., Madrid, 1960), vols. II-III. La excepción es el documento número 782, el tratado entre Alfonso VIII de Castilla y Alfonso IX de León, fechado el 26 de marzo de 1206 . Aunque durante los reinados de Alfonso VIII y Enrique I había pocos documentos originales enteros en la lengua vernácula que se hayan conservado, voces y frases en romance aparecían en muchos documentos, tanto reales como no reales, desde el siglo X, según César HERNÁNDEZ, Acercamiento al castellano del siglo XIII, "Scripta philologica in honorem Juan M. Lope Blanch" (3 vols., México, 1991), I, p. 331, y Derek William Lomax, La lengua oficial de Castilla, "Actele celui de-al XII-lea Congres
} 
cancillería de Alfonso X (1252-1284) estában en romance (salvo cierta correspondencia con extranjeros; véase la nota 6). De aquí se concluye que el reinado de Fernando III (1217-1252) fue la época principal de transición entre el uso predominante del latín y el posterior uso del romance. Después de señalar en el próximo párrafo algunas características de los documentos expedidos por la cancillería fernandina, en la sección segunda de este artículo trato de averiguar la fecha del cambio de lenguas observado en ellos. En la sección tercera, identifico algunas personas que jugaron un papel decisivo en efectuar el cambio. En la cuarta y última sección, llamo la atención sobre el periodo aproximado en el cual el reconocimiento del latín y del romance, como lenguas distintas se documenta, y después se generaliza en la práctica cancilleresca.

\subsection{TIPOLOGÍA DE DOCUMENTOS CANCILLERESCOS}

La cancillería real fue el oficio desde el cual el rey, a través de su canciller y el personal subordinado, validaba leyes formalmente al publicarlas $^{5}$. Diferentes categorías de documentos identifican comunicaciones de mayor o menor solemnidad según el propósito y el contenido de sus textos. Las categorías básicas abarcan privilegios rodados (los diplomas más

International de Linguistică şi Filologia Romanică" (2 vols., Bucarest, 1971), II, pp. 412. Mi conservadurismo al emplear solamente (o primariamente según el caso notado) documentos originales va dirigido a realzar la fiabilidad de mis conclusiones, especialmente porque la falsificación o adulteración de textos era una práctica no infrecuente; ejemplos entre los documentos fernandinos contenidos en GONZÁLEZ son los números $73,522,561,777$ y 783. Muchas copias posteriores de documentos originales eran inexactas, revisadas o de otro modo defectuosas, una situación bien conocida al paleógrafo y al filólogo.

${ }^{5}$ Una bibliografía sobre la cancillería castellana en la primera mitad del siglo XIII debe incluir los estudios siguientes mencionados en este artículo: Julio GONZÁLEZ, Reinado y diplomas de Fernando III ( 3 vols., Córdoba, 1980-1986), I, pp. 504-555; LOMAX, La lengua oficial, pp. 411-417; Antonio J. LÓPEZ GUTIÉRREZ, La cancillería de Fernando III, Rey de Castilla y León (1230-1253) [sic], "Archivo Hispalense", LXXVII (1994), pp. 71-81; Agustín MillaRes CARLo, La cancillería real en León y Castilla hasta fines del reinado de Fernando III, "Ánuario de Historia del Derecho Español", III (1926), pp. 227-306; E[velyn] S. PROCTER, The Castilian Chancery during the Reign of Alfonso X, 1252-84, "Oxford Essays in Medieval History Presented to Herbert Edward Salter" (Oxford: Clarendon Press, 1934); Luciano SERrano, El canciller de Fernando III de Castilla, "Hispania", V (1941), pp. 3-40; Roger WRIGHT, Latin and Romance in the Castilian Chancery (1180-1230), "Bulletin of Hispanic Studies", LXXIII (Liverpool, 1996), pp. 115-128. He tratado algunos aspectos de la materia en mi edición del Libro de las tahurerías de Maestro Roldán (Madison: Hispanic Seminary of Medieval Studies, 1995), Apéndice 4, I 14.a y notas. 
solemnes y formales), otras cartas, cuadernos de Cortes y códigos legales. Se prescriben y se describen las formas de los dos primeros grupos en el Espéculo y en las Siete Partidas atribuidos a Alfonso $\mathrm{X}^{6}$. En los párrafos que vienen a continuación se presta atención a los privilegios, las otras cartas reales y los dos códigos mencionados. Con respecto a las Cortes de Castilla, antiguamente se atribuían a Alfonso $\mathrm{X}$ los primeros documentos en la lengua vernácula que trataban de sus asuntos, pero hoy se sabe que la documentación de las Cortes de 1207, convocadas por Alfonso VIII, y la de las Cortes de 1250, convocadas por Fernando III, se conserva en una copia contemporánea y en el diploma original respectivamente, ambos documentos en romance. Los cuadernos existentes de Alfonso X no contienen más que los juicios del rey sobre las peticiones que le habían dirigido miembros de uno $\mathrm{u}$ otro estamento. Aunque en los cuadernos referidos no se citan las peticiones, a veces se resumen los puntos principales o por lo menos se menciona lo esencial del asunto al principio de la respuesta correspondiente. Cuando a villas distintas se les mandaban cuadernos sobre las mismas Cortes, los ejemplos conocidos muestran una variación dialectal entre ellos normalmente debida a la lengua empleada por los destinatarios. Pero cierto dialecto en una comunicación también podía reflejar el lugar de origen, y por eso la influencia lingüística, de cierto escriba en la cancillería ${ }^{7}$.

${ }^{6}$ Espéculo, ed. Robert A. MACDonald, Madison, 1990, IV.12, notablemente la Ley 13 sobre privilegios rodados y Leyes 17-45 sobre otros tipos de cartas. Partida Segunda, ed. Real Ácademia de la Historia (3 vols., Madrid, 1807), Título III, Ley XVIII. Acerca de la descripción y la historia del privilegio rodado véase Gaspar IBÁÑEZ, Marqués de Mondéjar, Madrid, 1777, Libro VII, capítulos V-VI; MILLARES CARLO, La cancillería real, especialmente pp. 234 y ss.; PROCTER, The Castilian Chancery, pp. 106-109 (donde la insigne hispanista inglesa observó algunas diferencias entre las prácticas fernandina y alfonsina por un lado y por otro lado la prescripción en los referidos códigos del rey Sabio); Antonio C. FloRiano CumBreño, Curso general de paleografía (2 vols., Oviedo, 1946), I, pp. 509-523; GonZÁLEZ, Fernando III, I, pp. 513-524; y los estudios en Sevilla, ciudad de privilegios, Sevilla, 1995. Para ver la descripción e historia de otras cartas reales consúltense PROCTER, pp. 109-111 FloRIANO CUMBREÑO, I, pp. 523-555; y GONZÁLEZ, I, pp. 524-555. Por brevedad puse otras cartas y actas reales en esta categoría. Aunque en los códigos alfonsinos el latín fue la lengua prescrita para correspondencia dirigida al extranjero, PROCTER, ob. cit., p. 105, nota 2, observó que en realidad "Castilian as well as Latin was used in foreign correspondence; letters to the kings of Portugal are in Castilian, those to the kings of Aragon in either language, very occasionally letters to the kings of England are in Castilian".

${ }^{7}$ Para ver el texto de un cuaderno de las Cortes de 1207 véase Francisco J. HERnÁNDEZ, Las Cortes de Toledo de 1207, "Las Cortes de Castilla y León en la Edad Media" (2 vols., Valladolid, 1988), I, pp. 219-263, con el texto en pp. 240-246. Para obtener información semejante sobre las Cortes de 1250 véase PROCTER, Curia and Cortes in León and Castile 10721295 , Cambridge University Press, 1980, pp. 124-125, con el texto de un cuaderno hasta entonces no publicado contenido en el Apéndice de Documentos, número 111. Ignoro otros 


\subsection{DATANDO LOS PRIMEROS USOS DEL ROMANCE EN LA CANCILLERÍA CASTELLANA. PRIVILEGIOS RODADOS}

A continuación se presenta una lista de los veintinueve privilegios rodados expedidos durante el reinado de Fernando III, comenzando con el primero en romance, de 1233, conocidos a González y notados por él como diplomas originales ${ }^{8}$. En la tabla la lengua señalada como latín (L) o castellano (C) es la del cuerpo del documento, es decir, de la substancia del mensaje comunicado (véase la nota 9). Los números 9-12 inclusive, cercanos cronológicamente y todos en latín, se dirigían a la Orden de Santiago. El número 19 es una copia, hecha durante el mismo reinado, del privilegio original fechado en 1242. Claro que el número total de documentos en esta tabla y en las dos que la siguen no corresponde necesariamente al número total de tales documentos expedidos de hecho durante el reinado referido.

cuadernos de Cortes existentes para el reinado de Fernando III; cf. Cortes de los antiguos reinos de Leon y de Castilla (5 tomos en 7 vols., Madrid, 1861-1903), I. Del número de Cortes de Castilla que algunos historiadores han propuesto para esta época las "best authenticated" fueron pocas: en 1217, 1219, 1222 y 1250, según PROCTER, ob. cit., pp. 116-117, 152; sus conclusiones ponderadas incluyen también el trabajo de Joseph F. O'CALLAGHAN, The Beginnings of the Cortes of León-Castile, "American Historical Review", LXXIV (1969), pp. 1503-1537, si o no se han encontrado los textos de los cuadernos relevantes. Los cuadernos de Cortes no siempre se reconocen como tales, de manera que alguno que otro todavía puede ver la luz; cf. F. HERNÁNDEZ, ob. cit., especialmente pp. 221-222. Para examinar textos del reinado de Alfonso X refiérase a Cortes, I, números XIII (1258), XIV (1268) y XVI (1274), el último de los cuales, en la forma conocida, no es el documento original, sino una versión hecha en siglos posteriores y en parte tomada del texto original y en parte basada en paráfrasis. En los cuadernos la diferenciación específica entre una petición y la respuesta del rey empezó durante la minoría de Alfonso XI con una paráfrasis más sustancial de cada petición. Para referencia a los dialectos en obras originales de las cancillerías fernandina y alfonsina véase, abajo, la nota 29.

${ }^{8}$ Por el momento utilizo 'romance' para incluir dialectos y subdialectos (o variaciones) tanto hispánicos no castellanos como castellanos, incluyendo casos donde la lengua claramente predominante en los documentos en GonZÁLEZ, Fernando III, es el castellano. Atestiguan la autenticidad de un privilegio rodado la presencia de un sello o indicios de él, o su lugar y su medio de enlace con el documento. GONZÁLEZ no anota ningún privilegio rodado del año 1247, una circunstancia quizá relacionada con la ausencia en el extranjero, y luego la muerte en el mismo año, del latinista influyente y canciller de muchos años, el arzobispo Rodrigo Jiménez de Rada. 


$\begin{array}{ccll} & \begin{array}{c}\text { Número en } \\ \text { González }\end{array} & \text { Fecha del privilegio } & \text { Lengua }^{9} \\ \text { 1. } & 506 & 29 \text { nov. } 1233 & \mathrm{C} \\ 2 . & 519 & 24 \text { abr. } 1234 & \mathrm{C} \\ 3 . & 629 & 31 \text { ag. } 1238 & \mathrm{C} \\ 4 . & 649 & 20 \text { jun. } 1239 & \mathrm{C}^{10} \\ 5 . & 705 & 18 \text { feb. } 1243 & \mathrm{C} \\ 6 . & 708 & 6 \text { abr. } 1243 & \mathrm{~L} \\ 7 . & 710 & 20 \text { abr. } 1243 & \mathrm{C} \\ 8 . & 713 & 24 \text { jul. } 1243 & \mathrm{~L} \\ 9 . & 714 & 5 \text { sep. } 1243 & \mathrm{~L} \\ 10 . & 715 & 10 \text { sep. } 1243 & \mathrm{~L} \\ 11 . & 716 & 11 \text { sep. } 1243 & \mathrm{~L} \\ 12 . & 717 & 13 \text { sep. } 1243 & \mathrm{~L} \\ 13 . & 730 & 31 \text { dic. } 1245 & \mathrm{~L} \\ 14 . & 732 & 4 \text { ene. } 1246 & \mathrm{C} \\ 15 . & 733 & 16 \text { ene. } 1246 & \mathrm{C} \\ 16 . & 753 & 11 \text { ene. } 1248 & \mathrm{C} \\ 17 . & 754 & 15 \text { ene. } 1248 & \mathrm{C} \\ 18 . & 756 & 27 \text { ene. } 1248 & \mathrm{C} \\ 19 . & 760 & 15 \text { mayo } 1248 & \mathrm{~L} \\ 20 . & 762 & 20 \text { mayo } 1248 & \mathrm{C} \\ 21 . & 763 & 28 \text { mayo } 1248 & \mathrm{C} \\ 22 . & 764 & 28 \text { mayo } 1248 & \mathrm{C} \\ 23 . & 775 & 16 \text { feb. } 1249 & \mathrm{~L} \\ 24 . & 779 & 26 \text { mar. } 1249 & \mathrm{~L} \\ 25 . & 789 & 23 \text { abr. } 1250 & \mathrm{C} \\ 26 . & 820 & 26 \text { abr. } 1251 & \mathrm{C}\end{array}$

${ }^{9}$ Todas (como en el número 22) o una parte (como en el número 26) de las últimas frases - la comninatoria, el anuncio de la validación, la fecha y el lugar de despacho, la corroboración y subscripción real y de infantes, prelados, magnates laicos y merinos mayores- están en latín, aun cuando las frases introductorias y el cuerpo del documento están en romance (como en el número 1). También en documentos en castellano, la introducción puede estar en latín (como en el número 64 en la próxima tabla).

${ }^{10}$ Todos los privilegios rodados anteriores a la fecha del número 5 están en latín y se listan en la nota 11 . 


$\begin{array}{llll}27 . & 823 & 22 \text { mayo } 1251 & \text { L } \\ 28 . & 839 & 20 \text { mar, 1252 } & \text { C } \\ 29 . & 843 & 25 \text { abr. 1252 } & \text { C }\end{array}$

Según la tabla anterior se disciernen tres períodos de cambio en la elección de lengua. En el primero, desde 1217 hasta 1233, el privilegio rodado aparecía sólo en latín. En el segundo, desde 1233 hasta fines de 1245 , este tipo de documento aparecía en romance esporádicamente (6 ocasiones) mientras la gran mayoría (50 instancias ciertas y 4 cuya originalidad es posible o probable) seguía escribiéndose en latín ${ }^{11}$. En el tercer período, desde 1246 hasta el fin del reinado en mayo de 1252 , el romance predominaba, empleado tres veces por cada vez que se empleaba el latín. Sobre la base del uso en los privilegios rodados, por lo tanto, se infiere que la época cuando el romance llegó a predominar estaba en el período desde enero de 1246 hasta enero de 1248 (faltan ejemplos intermedios). Apareció exclusivamente tan temprano como en junio de 1251 y no más tarde de marzo de 1252.

\subsection{OTROS PRIVILEGIOS Y CARTAS}

A continuación, se presenta una lista de sesenta y cinco cartas reales en castellano, todas, según González, originarias de la cancillería fernandina (se excluyen copias hechas en el reinado de Alfonso $\mathrm{X}$ y después). Se señalan con un punto de interrogación los documentos de cuya originalidad González no estaba seguro. En esta tabla y en la que le sigue, se refiere 'romanceado' a la lengua vernácula de la copia posfernandina cuyo texto original y lugar actual son desconocidos, y por eso cuya lengua queda incierta. Los privilegios rodados están omitidos en la suma.

\footnotetext{
"En la tabla se listan todos los privilegios rodados en castellano. Los que están en latín, además de los cinco primeros de la tabla, en GonZÁLEZ, Fernando III, son los números 509, $514,521,527,529,532,546,551,553,554$ ?, 555, 558? $575,576,580,581,582$ ?, 583$587,593,597,609-611,613,614,616,624,625,627,652-654,657,663,666,672,677,685$, $686,700,701$.
} 


\begin{tabular}{|c|c|c|c|c|c|}
\hline & $\begin{array}{l}N^{o} \text { en } \\
\text { González }\end{array}$ & $\begin{array}{l}\text { Fecha carta } \\
\text { original en } \\
\text { castellano }\end{array}$ & $\begin{array}{l}N^{o} \text { cartas } \\
\text { romancea } \\
\text { castesde } \\
\text { varta pre- }\end{array}$ & $\begin{array}{l}N^{o} \text { carta- } \\
\text { sen Gattn } \\
\text { desde } \\
\text { utima } \\
\text { orlginal } \\
\text { enc caste- } \\
\text { elano }\end{array}$ & \\
\hline & & & & Original & $\begin{array}{l}\text { No } \\
\text { orig }\end{array}$ \\
\hline 1. & 183 & 11 jul, 1223 & -- & -- & -- \\
\hline 2. & 227 & 18 ag. 1227 & 1 & 4 & 8 \\
\hline 3. & 235 & 20 jun. 1228 & 1 & 0 & 4 \\
\hline 4. & $236(?)$ & 23 jun. 1228 & 0 & 0 & 0 \\
\hline 5 & 246 & 7 feb. 1229 & 3 & 0 & 0 \\
\hline 6. & 262 & 25 ene. 1230 & 3 & 2 & 1 \\
\hline 7. & 263 & 27 ene. 1230 & 0 & 0 & 0 \\
\hline 8. & 283 & 4 ene. 1231 & 1 & 3 & 5 \\
\hline 9. & 305 & 16 feb. 1231 & 1 & 1 & 9 \\
\hline 10. & 334 & 15 mayo 1231 & 6 & 1 & 8 \\
\hline 11. & 356 & 21 oct. 1231 & 0 & 3 & 7 \\
\hline 12. & 378 & 20 dic. 1231 & 0 & 3 & 8 \\
\hline 13. & 478 & 30 jul. 1232 & 1 & 10 & 33 \\
\hline 14. & 504 & 12 nov. 1233 & 3 & 0 & 8 \\
\hline 15. & 515 & 28 mar. 1234 & 2 & 2 & 3 \\
\hline 16. & 520 & 24 abr. 1234 & 2 & 0 & 1 \\
\hline 17. & 526 & 4 jul. 1234 & 1 & 0 & 2 \\
\hline 18. & 534 & 22 sep. 1234 & 0 & 2 & 0 \\
\hline 19. & 591 & 31 ene. 1237 & 16 & 3 & 9 \\
\hline 20. & 594 & 28 feb. 1237 & 0 & 0 & 1 \\
\hline 21 & 595 & 2 mar. 1237 & 0 & 0 & 0 \\
\hline 22. & 600 & 28 abr. 1237 & 2 & 1 & 1 \\
\hline 23. & 617 & 6 mar. 1238 & 4 & 1 & 4 \\
\hline 24. & 622 & 26 abr. 1238 & 2 & 0 & 1 \\
\hline 25. & 631 & 9 oct. 1238 & 2 & 0 & 1 \\
\hline 26. & 658 & 30 nov. 1239 & 4 & 2 & 8 \\
\hline 27. & 662 & 15 dic. 1239 & 0 & 0 & 3 \\
\hline 28. & 668 & 20 feb. 1241 & 0 & 0 & 2 \\
\hline 29. & 670 & 3 mar. 1241 & 1 & 0 & 0 \\
\hline 30. & 675 & 12 mar. 1241 & 3 & 0 & 0 \\
\hline 31. & 676 & 8 abr. 1241 & 0 & 0 & 0 \\
\hline
\end{tabular}




\begin{tabular}{|c|c|c|c|c|c|}
\hline 32. & 678 & 19 abr. 1241 & 0 & 0 & 0 \\
\hline 33. & 682 & 8 jul. 1241 & 1 & 0 & 0 \\
\hline 34. & 694 & 20 mar. 1242 & 3 & 1 & 2 \\
\hline 35. & 696 & 22 mar. 1242 & 1 & 0 & 0 \\
\hline 36. & 702 & 28 sep. 1242 & 1 & 0 & 1 \\
\hline 37. & 707 & 2 abr. 1243 & 3 & 0 & 0 \\
\hline 38. & 711 & 22 abr. 1243 & 1 & 0 & 0 \\
\hline 39. & 738 & 31 mar. 1246 & 6 & 2 & 5 \\
\hline 40. & 743 & 15 sep. 1246 & 3 & 0 & 0 \\
\hline 41. & 744 & 26 sep. 1246 & 0 & 0 & 0 \\
\hline 42. & 748 & 22 0ct. 1247 & 2 & 0 & 0 \\
\hline 43. & 749 & 1 dic. 1247 & 0 & 0 & 0 \\
\hline 44 & 750 & 10 dic. 1247 & 0 & 0 & 0 \\
\hline 45. & 768 & 20 nov. 1248 & 6 & 2 & 0 \\
\hline 46. & 778 & 24 mar. 1249 & 3 & 0 & 4 \\
\hline 47. & 802 & 15 jul. 1250 & 13 & 0 & 3 \\
\hline 48. & 805 & 1 oct. 1250 & 2 & 0 & 0 \\
\hline 49. & 806 & 10 oct. 1250 & 0 & 0 & 0 \\
\hline 50 & 809 & 18 nov. 1250 & 2 & 0 & 0 \\
\hline 51. & 810 & 20 nov. 1250 & 0 & 0 & 0 \\
\hline 52. & 811 & 12 dic. 1250 & 0 & 0 & 0 \\
\hline 53. & 813 & 6 ene. 1251 & 0 & 0 & 0 \\
\hline 54. & 816 & 25 ene. 1251 & 1 & 0 & 0 \\
\hline 55. & 818 & 25 mar. 1251 & 1 & 0 & 0 \\
\hline 56. & 819 & 13 abr. 1251 & 0 & 0 & 0 \\
\hline 57. & 822 & 18 mayo 1251 & 1 & 0 & 0 \\
\hline 58. & 824 & 14 jun. 1251 & 0 & 1 & 0 \\
\hline 59. & 827 & 9 jul. 1251 & 1 & 0 & 0 \\
\hline 60. & $832(?)$ & 15 nov. 1251 & 2 & 0 & 2 \\
\hline 61. & 838 & 12 mar. 1252 & 5 & 0 & 0 \\
\hline 62. & 842 & 22 abr. 1252 & 1 & 0 & 0 \\
\hline 63. & 844 & 26 abr. 1252 & 0 & 0 & 0 \\
\hline 64. & 845 & 26 abr. 1252 & 0 & 0 & 0 \\
\hline 65. & 848 & 18 mayo 1252 & 2 & 0 & 0 \\
\hline
\end{tabular}


Esta tabla muestra que en las cartas reales se usaba solamente el latín desde el principio del reinado en 1217 hasta mediados de 1223. Después el asunto se obscurece a causa del gran número de cartas en romance postfernandinas. Muchas de estas cartas son copias de la cancillería de Alfonso $\mathrm{X}$ pero, ya que los indicios señalan claramente que los estudiosos alfonsinos preferían traducir al romance los libros y documentos escritos en otra lengua, determinar si el diploma fernandino se había escrito en latín o en romance no es posible sin encontrar pruebas fehacientes sobre el uno o el otro. De todos modos, desde aproximadamente 1237 hasta 1241 hubo un período de equilibrio en el número de cartas en latín y en castellano, al menos entre los documentos originales citados. Después de este intervalo, las cartas en latín aparecían esporádicamente, y desde no más tarde de mediados de 1250 el uso del castellano era casi exclusivo. Las fechas de la clara preferencia por el uso del romance en los privilegios rodados y en otras cartas reales no distan mucho una de otra (más o menos cinco años: 1246 y 1241 respectivamente) aunque en el caso de las cartas su primera aparición fue un decenio antes de la del más solemne y prestigioso privilegio rodado. La naturaleza del privilegio evocaba un tratamiento más conservador en el lenguaje y en la forma, explicando así el empleo posterior del romance en este tipo de diploma.

\subsection{OTROS DOCUMENTOS LEGISLATIVOS}

Se ignora la existencia de la mayoría de los cuadernos de Cortes que tuvieron su origen en el reinado de Fernando III (arriba, § 1.3). Mientras en toda posibilidad durắnte los últimos años de este rey se comenzaron planes para codificar el derecho de Castilla ${ }^{12}$, en el curso del reinado la expresión mayor y más temprana de la legislación superior ocurrió en la forma de fueros o de documentos que trataban de ellos. Cuarenta y seis textos legislativos que versaban sobre asuntos específicamente forales componen la próxima tabla. En gran parte consisten en concesiones de fueros municipales por Fernando III o representan sus confirmaciones de fueros otorgados por reyes anteriores. Unos pocos de los documentos resuelven litigios en el

\footnotetext{
${ }^{12}$ Eseribí algunas palabras sobre esto en mi edición del Espéculo alfonsino, capítulo 9.7 de la introducción, y también en la del Libro de las tahurerías de Maestro Roldán, capítulo 8.1-.2.
} 
derecho foral. Donde en la tabla se encuentra 'R', por 'romanceado', la copia existente es de una fecha posfernandina entre los siglos XIII y XVIII inclusive y es sin referencia a un dialecto específico aunque normalmente se entiende el castellano o una variedad de ella.

\section{$N^{o}$ en Fecha \\ González}

$\begin{array}{ccl}1 . & 9 & 1 \text { dic. } 1217 \\ 2 . & 29 & 6 \text { mayo } 1218 \\ 3 . & 75 & 26 \text { mayo } 1219 \\ 4 . & 83 & 18 \text { jul. } 1219 \\ 5 . & 86 & 31 \text { jul. } 1219 \\ 6 . & 90 & 23 \text { ag. } 1219 \\ 7 . & 92 & 22 \text { sep. } 1219 \\ 8 . & 95 & 16 \text { dic. } 1219 \\ 9 . & 127 & 29 \text { ene. } 1221 \\ 10 . & 131 & 31 \text { mar. } 1221 \\ 11 . & 137 & 25 \text { jul. } 1221 \\ 12 . & 151 & 16 \text { ene. } 1222 \\ 13 . & 154 & 24 \text { ene. } 1222 \\ 14 . & 162 & 7 \text { abr. } 1222 \\ 15 . & 166 & 17 \text { jul. } 1222 \\ 16 . & 167 & 22 \text { jul. } 1222 \\ 17 . & 168 & 23 \text { jul. } 1222 \\ 18 . & 169 & 24 \text { jul. } 1222 \\ 19 . & 220 & 10 \text { dic. } 1226 \\ 20 . & 224 & 27 \text { mar. } 1227 \\ 21 . & 253 & 25 \text { sep. } 1229 \\ 22 . & 272 & 19 \text { dic. } 1230 \\ 23 . & 316 & 2 \text { abr. } 1231 \\ 24 . & 386 & 19 \text { ene. } 1232 \\ 25 . & 429 & 12 \text { mar. } 1232 \\ 26 . & 480 & 29 \text { ag. } 1232 \\ 27 . & 488 & 1 \text { nov. } 1232 \\ 28 . & 513 & 3 \text { mar. } 1234\end{array}$

\begin{tabular}{|c|c|c|}
\hline $\begin{array}{l}\text { Priv. } \\
\text { rodado u } \\
\text { otro doc. }\end{array}$ & $\begin{array}{l}\text { ¿Documen- } \\
\text { to original? }\end{array}$ & $\begin{array}{l}\text { Lengua } \\
\text { del } \\
\text { cuerpo }\end{array}$ \\
\hline p.r. & -- & $\mathrm{L}$ \\
\hline p.r. & orig. & $\mathrm{L}$ \\
\hline p.r. & -- & $\mathrm{R}$ \\
\hline -- & -- & $\mathrm{L}$ \\
\hline -- & -- & $\mathbf{R}$ \\
\hline p.r. & orig. & $\mathrm{L}$ \\
\hline -- & -- & $\mathrm{L}$ \\
\hline p.r. & orig. & $\mathrm{L}$ \\
\hline p.r. & -- & $\mathrm{L}$ \\
\hline-- & -- & $\mathrm{L}$ \\
\hline-- & -- & $\mathrm{L}$ \\
\hline-- & -- & $\mathrm{L}$ \\
\hline p.r. & orig. & $\mathrm{L}$ \\
\hline-- & -- & $\mathrm{L}$ \\
\hline p.r. & -- & $\mathrm{L}$ \\
\hline -- & -- & $\mathbf{R}$ \\
\hline p.r. & -- & $\mathrm{L}$ \\
\hline p.r. & orig. & $\mathrm{L}$ \\
\hline-- & -- & $\mathrm{R}$ \\
\hline-- & -- & $\mathrm{L}$ \\
\hline-- & -- & $\mathbf{R}$ \\
\hline p.r. & orig & $\mathbf{L}$ \\
\hline p.r. & -- & L \\
\hline p.r. & orig. & $\mathrm{L}$ \\
\hline-- & -- & $\mathrm{L}$ \\
\hline-- & -- & $\mathrm{R}$ \\
\hline p.r. & -- & $\mathrm{L}$ \\
\hline -- & -- & L \\
\hline
\end{tabular}




\begin{tabular}{|c|c|c|c|c|}
\hline 29. & 573 & $26 \mathrm{ag} .1236$ & -- & -- \\
\hline 30. & 597 & 20 mar. 1237 & p.r. & orig. \\
\hline 31. & 612 & 28 sep. 1237 & -- & -- \\
\hline 32. & 670 & 3 mar. 1241 & -- & orig. \\
\hline 33. & 674 & 10 mar. 1241 & -- & -- \\
\hline 34. & 677 & 8 abr. 1241 & p.r. & orig. \\
\hline 35. & 695 & 20 mar. 1242 & -- & -- \\
\hline 36. & 718 & 13 nov. 1243 & -- & -- \\
\hline 37. & 728 & 8 ag. 1245 & p.r. & -- \\
\hline 38. & 733 & 16 ene. 1246 & p.r. & orig. \\
\hline 39. & 794 & 4 jul. 1250 & p.r. & -- \\
\hline 40. & 798 & 9 jul. 1250 & -- & -- \\
\hline 41. & 809 & 18 nov. 1250 & -- & orig. \\
\hline 42. & 817 & 17 feb. 1251 & -- & -- \\
\hline 43. & 818 & 25 mar. 1251 & - & orig. \\
\hline 44. & 819 & 13 abr. 1251 & -- & orig. \\
\hline 45. & 825 & 15 jun. 1251 & p.r. & -- \\
\hline 46. & 847 & 8 mayo 1252 & -- & -- \\
\hline
\end{tabular}

Antes de 1246 se escribían todos los documentos forales en latín, algunos de los cuales existen hoy solamente en copias posteriores romanceadas. El primer documento fernandino original en castellano que se conoce hoy y que trata de fueros se fechó el 16 de enero de 1246. De los ocho que lo siguen en la tabla, cinco son versiones romanceadas cuyo texto original podría haber estado en latín o en la lengua vernácula. Una situación que puede servir de precursor del cambio en la preferencia de lenguas fue cuando el rey dio el fuero de Toledo a Córdoba en dos ocasiones, cada concesión contenida en un diploma considerado por González como original. En el primer documento, fechado el 3 de marzo de 1241, las disposiciones del fuero están en romance mientras el resto del texto está en latín. En el documento del 8 de abril del mismo año el texto entero está en latín ${ }^{13}$.

\footnotetext{
${ }^{13}$ En el documento del 3 de marzo (número 670 en GoNZÁLEZ, Fernando III) no se nombra el escriba ni se muestran la rueda ni la lista de confirmantes que debe contener el privilegio rodado. El segundo documento (número 677 en GoNZÁLEZ, ob. cit.) nota que fue escrito por Juan Pérez de Soria, copista que escribió solamente un privilegio más (número 685), que se
} 


\subsection{CONCLUSIÓN}

Sobre la base de la fecha de documentos existentes expedidos por la cancillería de Fernando III y cuya autenticidad es cierta, en la próxima tabla se resumen los tipos de documentos que contienen legislación real y se indica para cada tipo el primer documento original conocido cuyo cuerpo está en castellano y el primer documento original conocido totalmente (o casi) en castellano.

\section{Tipo de legislación real}

Privilegios rodados

La mayoría de otras cartas

Cartas sobre asuntos forales

\section{Primer documento cuyo cuerpo está en castellano}

noviembre 1233

julio 1223

enero 1246
Primer documento exclusivamente (o casi) en castellano

abril 1250

marzo 1246

enero 1246

En esta tabla la discrepancia entre fechas de tipos diferentes de diploma tiene su explicación en la escasez de ejemplos de un tipo con

sepa, también original y en latín. Quizá se pensaba que el documento fechado en marzo, expedido en Córdoba, debía servir de una obra de consulta a la mano de las autoridades locales; de todos modos el documento posterior, expedido en Toledo, fue la versión formal y completa, solemnizada en el formato y lenguaje tradicional del privilegio rodado. (Cuando el rey dio el Fuero de Córdoba a Cartagena el 16 de enero de 1246, en la copia romanceada del texto del fuero que acompañaba el documento de concesión se citó el 8 de abril de 1241 como la fecha y Toledo como el lugar de expedición, así reforzando la credibilidad de lo que se dice arriba). Ambos diplomas de 1241 contienen una disposición declarando que el Libro Iudgo (Fuero Juzgo) debía traducirse al castellano: "Otorgo et mando que el Libro Iudgo que les do yo, que ge lo mandare trasladar en romanz et que sea lamado fuero de Cordoua ... et nenguno sea osado de lamarle de otra guisa sinon fuero de Cordoua" (número 670); "statuo et mando quod Liber Iudicum quem ego dabo Cordubensibus translatetur in vulgare et vocatur forum de Corduba... Nullus sit ausus istud forum alias apellare nisi forum de Corduba" (número 677). La comparación de estos pasajes sugiere que la forma original y definitiva fuera la del 8 de abril. La versión romanceada del 3 de marzo puede representar o la primera y provisional versión mencionada - lo que parece ser más probable - o posiblemente una traducción posterior que sufrió una errata fácilmente cometida en la datación. Joaquín MELLADO RODRíGUEZ, El Fuero de Córdoba en su 750 aniversario, en "Actas del II Congreso de Historia de Andalucía[.] Córdoba, 1991[.] Historia medieval" (2 vols., Córdoba, 1994), I, p. 217, piensa que "... el rey mandó redactar apresuradamente un texto foral [el del 3 de marzo] a petición de los propios cordobeses...", pero MELLADO no presenta pruebas para sostener su afirmación. F. HERNÁNDEZ (Las Cortes de Toledo, Apéndice, p. 223) escribe de la copia del cuaderno de Cortes de 1207 que "fue realizada ... como instrumento de referencia", una descripción análoga a la que sugerí sobre el documento del 3 de marzo. 
respecto a otro y en mi omisión de todas las copias posfernandinas. Sin embargo, puede decirse de la cancillería durante el reinado de Fernando III que el período desde 1217 hasta 1223 atestiguó el uso exclusivo del latín. El período de transición del latín al castellano transcurrió entre 1223 y 1246/1248. El uso exclusivo o casi exclusivo del castellano (fuera de excepciones mandadas por el rey) ocurrió en los años finales del reinado, incluidos todos los textos conocidos desde julio de 1251 hasta mayo de 1252 . En otras palabras, el proceso de vernacularización en los documentos cancillerescos debe considerarse finalizado aproximadamente un año antes de la muerte de Fernando y del fin de su reinado.

\subsection{PERSONAL: CANCILlERES NOMINALES O EN FUNCIONES}

Los cancilleres nominales de Castilla y León desde la unión de los dos reinos en 1230 (y desde algún tiempo antes) fueron los arzobispos de Toledo y de Santiago respectivamente. Es obvio que ni el uno ni el otro habrían tenido tiempo para supervisar los numerosos negocios importantes de la cancillería real además de realizar los deberes relacionados con su oficio eclesiástico y con la cancillería archiepiscopal. Por eso uno de los arzobispos de Toledo, Rodrigo Jiménez de Rada, dio licencia y delegó poderes en un sustituto, nombrado por el rey, que actuara como su lugarteniente, esto es, como el jefe en funciones de la cancillería real. En la próxima tabla se lista el nombre de cada arzobispo de Toledo y canciller nominal de Castilla durante el reinado de Fernando III. Aunque en los privilegios rodados de este reinado no se registra ningún arzobispo específicamente con el título de canciller, se le llama así en los de Alfonso $\mathrm{X}$ desde $1255^{14}$. En las próximas dos tablas las fechas son las de los

\footnotetext{
${ }^{14}$ Como ha observado Pilar Ostos SAlCEdo, La cancillería de Fernando III, Rey de Castilla (1217-1230), "Archivo Hispalense", LXXVII (1994), pp. 59-70, se llamaba el canciller en funciones el vicecancillarius, o vicecanciller, en el documento 222 (GonZÁLEZ, Fernando III), un privilegio rodado original fechado el 16 de enero de 1227 . Se basa mi descripción del canciller y su oficio primariamente en las obras, citadas en la nota 5, de MILLARES CARLO y de SERRANO y en mis propias observaciones. Las fechas de los arzobispos son de Los primados de Toledo, Toledo, 1993, y, en el caso de Sancho de Castilla, de fichas biográficas que junté por los años. Sancho se titulaba canciller del rey desde el principio del reinado de su hermano (Alfonso X), pero en los privilegios rodados aparecía designado así por primera vez el 4 de febrero de 1255 (no lo fue el primero del mismo mes). Este hecho puede sugerir el tiempo cuando se instituyeron reformas y novedades contenidas en las disposiciones contenidas en el Espéculo. Uno sospecha que el papel activo del infante en la reorganización de la cancillería real
} 
primeros y de los últimos documentos conocidos que contienen los nombres citados. Documentos conservados que se hallan entre cada última fecha notada y la primera siguiente no identifican ni arzobispo ni canciller.

\title{
I. Toletane Sedis Archiepiscopus, Hyspaniarum Primas
}

1. Rodrigo Jiménez de Rada

27 feb. 1209-10 jun. 1247

2. Juan de Medina de Pomar

20 feb. $1248-20$ jul. 1248

3. Gutierre Ruiz de Olea

6 feb. $1249-9$ ag. 1250

4. Sancho, infante de Castilla

Procurador

$1251-1261$

Arzobispo electo

Arzobispo
7 mar. 1251-11 mar. 1251

26 abr. 1251-7 mar. 1259

9 abr./17 jun. $1259-27$ oct. 1261

En la tabla II ${ }^{\text {a }}$ se ven los jefes en funciones, o vicecancilleres, desde el principio del reinado fernandino y el oficio eclesiástico principal que tenía cada uno durante el período señalado. Se refleja aquí la mención explícita en latín del oficio en la cancillería real.

\section{II.A. Domini Regis Cancellarius}

1. Juan Díaz ${ }^{15}$

Abad de Santander
$1217-1246$

7 nov. $1217-16$ abr. 1220

\begin{abstract}
fuera inferior al del Maestro Ramón, pero la influencia de su juventud, educación y diligencia no deben descontarse demasiado pronto.

${ }^{15}$ Algunos habían pensado que el apellido del (vice)canciller era Domínguez, pero MILLARES CARLO (La cancillería, p. 283), citando documentos de la cancillería de Enrique I (en vez de los de la de Fernando III), estableció Díaz como el apellido correcto. El nombre y el apellido aparecen en el documento 80 (González), copia del original fechado el 22 de junio de 1219. El obispo de Burgos murió el primero de octubre de 1246. Para saber detalles biográficos véanse Millares Carlo, La cancillería, pp. 282-290; LomaX, La lengua oficial, p. 413; GONZÁLEZ, Fernando III, I, pp. 504-509; y WRIGHT, Latin and Romance, p. 121. Al escribir algunas inferencias disputables sobre Juan Díaz, WRIGHT nota que en un documento a finales del reinado de Enrique I que se titulaba el escriba, Juan Díaz, domini regis notarius. Queda incierto si en aquel momento notarius no era más que otro nombre de (vice)cancillarius o de 'escriba'. El obispo Juan Díaz era soriano.
\end{abstract}


Abad de Valladolid

Obispo electo de Osma

Obispo de Osma

Obispo de Burgos

2. Pedro Martínez ${ }^{16}$

Obispo electo de Jaén

Obispo de Jaén

\section{II.B. Domini Regis Notarius}

\section{Maestro Ramón de Losa- $\mathrm{na}^{17}$}

\section{Obispo de Segovia}

25 abr. 1220-1 mayo 1231

10 mayo $1231-24$ sep. 1232

17 oct. $1232-17$ sep. 1240

6 mar. 1241-28 ag. 1246

1249

15 ene. 1249 [-25 mayo 1249]

30 mayo 1249
$1250-1252$

20 abr. $1250-25$ abr. 1252

\footnotetext{
${ }^{16}$ Pedro Martínez todavía era Obispo electo de la diócesis de Jaén el 25 de mayo de 1249. según una carta papal de esta fecha reproducida por Augusto QUINTANA PRIETO en La documentación pontificia de Inocencio IV, Roma, 1987, número 581. Para otros datos véase Martín DE XIMENA JURADO, Catálogo de los obispos de las iglesias catedrales de Jaen y anales eclesiásticos de este obispado, Madrid, 1652; edición facsímil, Granada, 1991, pp. 209-211; cf. GonZÁlEZ, Fernando III, I, p. 509. El obispo murió camino de su sede nueva hacia finales de 1249 o a comienzos de 1250 (Peter LINEHAN, The Spanish Church and the Papacy in the Thirteenth Century, Cambridge University Press, 1971, p. 234, escribe, sin citar fuente, que Pedro estaba de regreso de Rocamador). En un privilegio rodado del 20 de abril de 1250 (número 788, GonZÁLEZ, ob. cit.) ya se llama Maestro Ramón el Notario del Rey. La sede de Jaén, no mencionada en aquel documento, tres días después se nota como vacante (número 789 ). Pedro Martínez era soriano.

${ }^{17}$ Después de la muerte del obispo Rodrigo de Segovia el 19 de diciembre de 1249, fue nombrado Maestro Ramón su sucesor en una fecha entre el 10 de enero y el 20 de abril de 1250. (Se saca la fecha cuando murió D. Rodrigo de Diego DE COLMENARES, Historia de la insigne ciudad de Segovia y compendio de las historias de Castilla [3 vols., Segovia, 1637; edición anotada, 1969-1975], I, Libro XXI, capítulo XIII, nota 91). Maestro Ramón vivió desde ca. 1218 hasta agosto de 1286 , y no hasta 1288 como dicen algunos; cf. Mercedes GaIBROIS DE BALLESTEROS, Sancho IV de Castilla (3 vols., Madrid, 1922-1928), III, números 124 y 127. Natural de Losana en la provincia moderna de Segovia, llegó a ser confesor y secretario de Fernando III. Se asoció directamente con la administración real centrada en la cancillería del rey. Más tarde fue nombrado Arzobispo de Sevilla. Seguía ejerciendo mucha influencia con el rey por todo el reinado de Alfonso X, y fue nombrado padrino del futuro rey Sancho IV. Para saber más información biográfica sobre Maestro Ramón véanse A[ntonio] BALLESTEROS [BeretTa], Sevilla en el siglo XIII, Madrid, 1913. Apéndice G, y Don Remondo de Losana, Obispo de Segovia, "Correo Erudito", I (1940-1941), pp. 313-318; Hilario SANZ Y SANZ, Don Raimundo de Losana, "Estudios Segovianos", XVIII (1966), pp. 47-60; y MACDONALD, edición del Espéculo, Apéndice V, número 11.
} 
En efecto, pues, el canciller nominal de Castilla, sin renunciar ninguna prerrogativa oficial, hizo que otro clérigo, elegido por el rey, sirviera de lugarteniente encargado de las tareas de cada día en la cancillería real. Hasta 1249 inclusive se documentan estos funcionarios con el nombre de [vice]cancillarii. Cuando el Maestro Ramón fue designado para el oficio, el nombre del oficial fue cambiado o corregido en regis notarius. No se puede determinar con precisión qué motivó el cambio ${ }^{18}$, pero es sabido que Maestro Ramón tuvo un papel importante en la reorganización de la cancillería y en el programa de reforma legislativa comenzado después de la toma de Sevilla (1248) y continuado, al morir Fernando, bajo su hijo y sucesor, Alfonso X. Debido a sus responsabilidades, deberes y contabilidad cancillerescos, se vinculó el notario mayor más estrechamente con el rey y, por lo menos en este respecto, menos tanto con el canciller nominal. Puede argüirse favorablemente que notarius era un título más exacto que cancillarius porque debía eliminar ambivalencia semántica en referencias al 'canciller'.

\subsection{ESCRIBAS EN LA CANCILLERÍA}

En el curso del reinado de Fernando III el número de escribas cuyos nombres se mencionan en diplomas cancillerescos era cuarenta y pico ${ }^{19}$. Se listan los nombres en la próxima tabla según la ortografía moderna. El número total de documentos en González en que se nombra el escriba

\footnotetext{
${ }^{18}$ LOPE GUTIÉRREZ, La cancillería, p. 74, relaciona con la muerte del obispo Pedro [1249?] y del Arzobispo Gutierre [Ruiz de Olea, Arzobispo de Toledo, 9 de agosto de 1250] la oportunidad que se le presentaba al rey para reorganizar la cancillería al nombrar a un infante como el arzobispo nuevo y la selección de un eclesiástico como notario mayor. De hecho, el sexto hijo de Fernando III, el infante Sancho, fue elegido hacia finales de 1250 aunque, debido a su juventud y al estado eclesiástico, el papa le nombró Procurador, y no Arzobispo, de la archidiócesis (carta fechado el 11 de marzo de 1251). Nombrado Notario Mayor fue el obispo de Burgos, Maestro Ramón.

${ }^{19} \mathrm{El}$ número, los datos y los nombres que figuran aquí y los correspondientes en la lista de GONZÁLEZ, Fernando III, I, p. 511, difieren por varias razones incluyendo inexactitudes en ésta. Se basó mi tabla en las transcripciones no paleográficas de González. Aunque no comparé palabra por palabra los textos manuscritos y los textos publicados por González, un examen superficial sugería que los errores fueran mínimos y que consistieran en erratas tipográficas. Aquí no identifico ni supervisores ni jefes de los escribas que funcionaban bajo el notario mayor.
} 
incluye privilegios rodados y otros tipos sin tener en cuenta si son originales o copias. En los casos de documentos originales se notan las lenguas empleadas como latín (L) o castellano (C) (ésta de vez en cuando muestra características en su vocabulario de otros dialectos romances; véase la nota 29) y, en el caso de una copia, una versión romanceada (R), las más veces castellano.

\begin{tabular}{|c|c|c|c|c|c|}
\hline Escriba & $\begin{array}{l}\text { Fechas de primera } \\
\text { y última presencia }\end{array}$ & $\begin{array}{l}\text { Núm. } \\
\text { total } \\
\text { docs. }\end{array}$ & & $\stackrel{\text { Igua }}{C}$ & $R$ \\
\hline 1. Diosayuda & $\begin{array}{l}20 \text { feb. } 1223,12 \\
\text { abr. } 1223\end{array}$ & 5 & 5 & 0 & 0 \\
\hline 2. Domingo Álvarez* & $\begin{array}{l}19 \text { mayo } 1218,16 \\
\text { jun. } 1227\end{array}$ & 13 & 12 & 0 & 1 \\
\hline 3. Domingo de Magaz* & 2 dic. 1217 & 1 & 1 & 0 & 0 \\
\hline 4. Domingo de Segovia & $\begin{array}{l}28 \text { nov. } 1217,27 \\
\text { abr. } 1230\end{array}$ & 31 & 31 & 0 & 0 \\
\hline 5. Domingo de Soria & $\begin{array}{l}7 \text { nov. } 1217,19 \text { ag. } \\
1221\end{array}$ & 17 & 17 & 0 & 0 \\
\hline $\begin{array}{l}\text { 6. Domingo García de } \\
\text { Segovia }\end{array}$ & 20 abr. 1243 & 1 & 0 & 1 & 0 \\
\hline 7. Domingo Ibáñez & $\begin{array}{l}29 \text { sep. } 1218,9 \text { ag. } \\
1223\end{array}$ & 5 & 4 & 0 & 1 \\
\hline $\begin{array}{l}\text { 8. Domingo Pérez de } \\
\text { Soria* }^{*}\end{array}$ & $\begin{array}{l}10 \text { ene. } 1218,12 \\
\text { nov. } 1238\end{array}$ & 7 & 7 & 0 & 0 \\
\hline 9. Esteban* & $\begin{array}{l}6 \text { sep. } 1217,6 \text { jun. } \\
1224\end{array}$ & 11 & 11 & 0 & 0 \\
\hline 10. Ferrando Ferrández & 24 abr. 1234 & 1 & 1 & 0 & 0 \\
\hline 11. Gil & $\begin{array}{l}2 \text { dic. } 1217,28 \\
\text { mayo } 1222\end{array}$ & 39 & 38 & 0 & 1 \\
\hline 12. García & $20 \mathrm{ag} .1251$ & 1 & 0 & 1 & 0 \\
\hline 13. Gonzalo Martínez & $\begin{array}{l}12 \text { abr. } 1230,18 \\
\text { mayo } 1252\end{array}$ & 17 & 15 & 2 & 0 \\
\hline
\end{tabular}




\begin{tabular}{|c|c|c|c|c|c|}
\hline 14. Gonzalo Sánchez & $\begin{array}{l}15 \text { nov. } 1251,7 \\
\text { dic. } 1251\end{array}$ & 2 & 0 & 2 & 0 \\
\hline 15. Juan de Aza* & $\begin{array}{l}7 \text { abr. } 1221,3 \\
\text { mayo } 1232\end{array}$ & 20 & 20 & 0 & 0 \\
\hline $\begin{array}{l}\text { 16. Juan Domínguez de } \\
\text { Segovia* }\end{array}$ & $\begin{array}{l}15 \text { feb. } 1251,26 \\
\text { abr. } 1252\end{array}$ & 8 & 0 & 8 & 0 \\
\hline 17. Juan Martínez & 17 feb. 1232 & 1 & 1 & 0 & 0 \\
\hline $\begin{array}{l}\text { 18. Juan Pérez de Ber- } \\
\text { langa* }\end{array}$ & $\begin{array}{l}23 \text { abril } 1250,28 \\
\text { abr. } 1251\end{array}$ & 8 & 0 & 8 & 0 \\
\hline $\begin{array}{l}\text { 19. Juan Pérez de Sego- } \\
\text { via* }^{*}\end{array}$ & $\begin{array}{l}20 \text { abr. } 1250,10 \\
\text { abr. } 1252\end{array}$ & 10 & 2 & 8 & 0 \\
\hline 20. Juan Pérez de Soria & $\begin{array}{l}8 \text { abr. } 1241,12 \text { jul. } \\
1241\end{array}$ & 2 & 2 & 0 & 0 \\
\hline $\begin{array}{l}\text { 21. Martín de Segovia, } \\
\text { Maestro* }\end{array}$ & $\begin{array}{l}4 \text { jul. } 1250,14 \text { dic. } \\
1251\end{array}$ & 3 & 0 & 3 & 0 \\
\hline 22. Martín de Soria & $\begin{array}{l}16 \text { jun. } 1223,20 \\
\text { jun. } 1238\end{array}$ & 2 & 1 & 1 & 0 \\
\hline 23. Martín Estébanez ${ }^{*}$ & $\begin{array}{l}7 \text { ene. } 1223,1 \text { oct. } \\
1228\end{array}$ & 10 & 10 & 0 & 0 \\
\hline 24. Martín Ibáñez & 5 sep. 1225 & 1 & 0 & 1 & 0 \\
\hline $\begin{array}{l}\text { 25. Martín Pérez, } \\
\text { canónigo de Segovia }\end{array}$ & 15 ene. 1237 & 1 & 1 & 0 & 0 \\
\hline 26. Miguel López & $\begin{array}{l}15 \text { mayo } 1248,16 \\
\text { feb. } 1249\end{array}$ & 3 & 3 & 0 & 0 \\
\hline $\begin{array}{l}\text { 27. Miguel Pérez de } \\
\text { Soria* }\end{array}$ & $\begin{array}{l}11 \text { sep. } 1243,12 \\
\text { mar. } 1252\end{array}$ & 4 & 1 & 3 & 0 \\
\hline 28. Pablo Sánchez & $\begin{array}{l}2 \text { sep. } 1231,29 \\
\text { feb. } 1232\end{array}$ & 5 & 5 & 0 & 0 \\
\hline 29. Pascasio de Soria* & $\begin{array}{l}7 \text { nov. } 1229,19 \\
\text { oct. } 1233\end{array}$ & 18 & 18 & 0 & 0 \\
\hline 30. Pedro Caro & 18 nov. 1250 & 1 & 0 & 1 & 0 \\
\hline
\end{tabular}




\begin{tabular}{|c|c|c|c|c|}
\hline 31. Pedro Cídez & $\begin{array}{l}21 \text { ene. } 1223,27 \\
\text { mar. } 1223\end{array}$ & 2 & 2 & 0 \\
\hline 32. Pedro de Soria & $\begin{array}{l}26 \text { nov. } 1217,16 \\
\text { jun. } 1219\end{array}$ & 2 & 2 & 0 \\
\hline $\begin{array}{l}\text { 33. Pedro Martínez de } \\
\text { Aguilar* }^{*}\end{array}$ & $\begin{array}{l}19 \text { dic. } 1231,18 \\
\text { oct. } 1239\end{array}$ & 31 & 31 & 0 \\
\hline 34. Pedro Núñez & 21 jul. 1241 & 1 & 1 & 0 \\
\hline $\begin{array}{l}\text { 35. Pedro Pérez de Za- } \\
\text { mora }^{*}\end{array}$ & $\begin{array}{l}22 \text { mar. } 1250,10 \\
\text { oct. } 1250\end{array}$ & 2 & 0 & 2 \\
\hline 36. Pedro Rodríguez & $\begin{array}{l}31 \text { oct. } 1228,30 \\
\text { jun. } 1232\end{array}$ & 2 & 2 & 0 \\
\hline 37. Román Aymárez & $\begin{array}{l}4 \text { oct. } 1225,2 \\
\text { mayo } 1226\end{array}$ & 2 & 2 & 0 \\
\hline 38. Sancho de Segovia* & $\begin{array}{l}20 \text { mayo } 1229,20 \\
\text { mar. } 1252\end{array}$ & 15 & 4 & 11 \\
\hline 39. Sancho Domínguez & 18 oct. 1239 & 3 & 3 & 0 \\
\hline 40. Sancho Estrosa & 8 ene, 1251 & 1 & 0 & 1 \\
\hline 41. Sancho Martínez & $\begin{array}{l}5 \text { mayo } 1250,20 \\
\text { nov. } 1250\end{array}$ & 4 & 0 & 4 \\
\hline
\end{tabular}

* 2. Solamente Domingo en 1 documento en latín, 7 jun. 1224.

3. Probablemente Magaz cerca de Palencia.

8. 'de Soria' incluido sólo en el primer documento.

9. Esteban Díaz in 1 documento en latín, 25 nov. 1239, excluido en el cuento.

15. Solamente Juan en 4 documents, 11 mar. 1226-18 ag. 1228.

16. Solamente Juan Domínguez en 6 documentos, 17 feb. 1251-26 abr. 1252 .

18. De las tres Berlanga -en las provincias de Badajoz, León y Soria- sería la soriana.

19. Solamente Juan Pérez en 1 documento en castellano, 12 mar. 1252. 

dic. 1251 .

21. Solamente Maestro Martín en 2 documents, 21 jun. 1251, 14

23. Solamente Martín en 4 documentos en latín, 8 dic. 1228-20 feb. 1232 , excluidos en el cuento.

27. Solamente Miguel Pérez en 3 documentos, 11 sep. 1243-12 mar. 1252 .

29. Solamente Pascasio en 17 documentos, 7 nov. 1229-19 oct. 1233.

33. Solamente Pedro Martínez en todos los documentos menos uno, 4 feb. 1237. Hay demasiados lugares del nombre Aguilar para que este sitio pueda identificarse.

34. Llamado notarius.

35. Solamente Pedro Pérez en 1 documento, 10 oct. 1250.

38. Solamente Sancho en 10 documentos, 20 mayo 1229-18 mayo 1251.

Se atribuyen los documentos en castellano a dieciséis de los cuarenta y un escribas. De los dieciséis, cinco escribían documentos en latín y en castellano. Las fechas extremas de los documentos en castellano siguen.

Escriba, más el número en la tabla arriba

13. Gonzalo Martínez

Fechas de documentos en castellano

19. Juan Pérez de Segovia

9 sep. 1251,18 mayo 1252

20 abr. $1250-10$ abr. 1252

20 jun. 1238

15 nov. 1251-12 mar. 1252

27 ene. $1248-20$ mar. 1252

Las primeras fechas de documentos en castellano escritos por los que escribían solamente en esta lengua resultan en la próxima lista.

Escriba, más su número

6. Domingo García de Segovia

12. García

14. Gonzalo Sánchez

16. Juan Domínguez de Segovia
Primera fecha del documen-

to en castellano

20 abr. 1243

20 ag. 1251

15 nov. 1251

17 feb. 1251 
18. Juan Pérez de Berlanga

21. Martín de Segovia, Maestro

24. Martín Ibáñez

30. Pedro Caro

35. Pedro Pérez de Zamora

40. Sancho Estrosa

41. Sancho Martínez
23 abr. 1250

4 jul. 1250

5 sep. 1225

18 nov. 1250

22 mar. 1250

8 ene. 1251

5 mayo 1250

En las dos tablas inmediatamente anteriores la fecha en los años 1225,1238 y 1243 no significan más que una vez el uso del romance por los escribas respectivos. Comenzando temprano en 1248, Sancho de Segovia escribía castellano en la mayoría de las ocasiones. En 1250 cinco copistas iniciaron el empleo exclusivo del castellano, y otros los seguían en 1251, el último año calendario completo del reinado de Fernando.

\subsection{PERSONAS INTERESADAS EN El CAMBio DE LENGUAS}

El uso exclusivo del romance en la legislación sobre asuntos forales empezó poco antes de la muerte del obispo Juan Díaz en 1246. Pero si el cambio en la práctica cancilleresca se debía a su influencia o a la de un jefe de escribas específico, o a otro escriba que le representaba antes de su muerte o después, es casi imposible determinar porque desde el otoño de 1243 hasta casi el fin de enero de 1248 los documentos existentes no muestran el nombre del escriba. El obispo Pedro bien podría haber sido responsable del uso del castellano en el importante número de cartas reales expedidas durante su breve oficio en 1249. Con respecto a los privilegios rodados se debía la extensión del mismo uso casi con certeza a la influencia o intervención del Maestro Ramón, nombrado Notario Mayor del Rey en Castilla en una fecha entre mayo de 1249 y mayo de 1250. Ya que en los varios tipos de documentos reales se adoptó el uso del romance en fechas diferentes, es muy posible que el cambio de lenguas no se debiera únicamente al juicio real, pero sin duda iba aprobado por Fernando III a medida que se veían más obvias las ventajas. En todo caso, durante el reinado de Alfonso $\mathrm{X}$ el nuevo uso correspondió a la prescripción expresada primero en el Espéculo y después en la Tercera Partida. 


\subsection{CONCLUSIÓN}

Es evidente que el cambio del uso del latín al uso del romance en documentos legislativos dirigidos a destinatarios locales e intrapeninsulares en el reinado de Fernando duró desde la primera carta conocida en castellano en 1223 hasta el uso casi exclusivo de esta lengua para 1250. Así que la época de transición correspondía principalmente al segundo cuarto del siglo XIII. La ultimación del proceso empezó con un impulso creciente poco antes de la muerte de Juan Díaz (1246). Se aceleró el ritmo en los dos años sucesivos, luego aumentó mucho bajo la notaría del Maestro Ramón. Para expresarlo de otra manera, el desarrollo del cambio, inicialmente lento, creció rápidamente en los años 1246-1250, al principio quizá con un sentido de la orientación nacido bajo, o aun a instancia de, el obispo Juan Díaz y luego, cada vez más, bajo la dirección de los obispos Pedro Martínez y, sobre todo, Maestro Ramón de Losana. Además, es muy posible que el lugar de origen de los copistas en la cancillería pueda ponerse en relación con el cambio de lenguas. Una contabilización revela que seis de los escribas (números 5, 8, 22, 27, 29, 32 arriba) añaden 'de Soria' después de su nombre, mientras siete (números $4,6,16,19,21,25,38$ ) agregan 'de Segovia' ${ }^{20}$. Ninguno de estos sorianos entró en su oficio después de 1246, la época cuando la castellanización de documentos legislativos comenzó a acelerarse notoriamente, mientras que tres de los segovianos $(16,19,21)$ entraron en servicio en 1250 o 1251 después de la investidura del Maestro Ramón, también de la región segoviana ${ }^{21}$.

\footnotetext{
${ }^{20} \mathrm{El} \mathrm{lugar}$ de origen añadido al nombre personal, como en los casos de Domingo de Soria y Domingo de Segovia, no se limitaba a señalar la villa nombrada; cf. SERRANO, El canciller, p. 4. Además, otros escribas, con o sin indicación de lugar, podían ser de otras partes de la región considerada soriana o segoviana. Por ejemplo, Maestro Ramón de Losana era de este pueblo en la parte oriental de la provincia moderna de Segovia, y un escriba sin 'de Soria' o 'de Segovia' en realidad podía ser o de una de estas villas o de la región cercana.

${ }^{21}$ Durante todo el reinado de Fernando III se expresaba la fecha y el lugar de expedición en latín, aun en documentos que en su parte principal salían en castellano. Sin embargo, una referencia a la práctica de identificar al escriba cuya responsabilidad era ejecutar un diploma en particular puede proyectar más luz en la fecha de modificaciones importantes en la preparación de privilegios rodados y otras cartas. Al examinar la presencia de identificación escribal en el curso del reinado, uno verá grados diferentes de constancia en la continuidad de la práctica. Me acerqué al punto comparando por cada año el número total de documentos expedidos (según GonZález, Fernando III), el número de ellos que incluía el nombre del escriba y el porcentaje de este número comparado con el número total. La escasez aparente de documentos en algunos años puede adscribirse al número desconocido de los perdidos, una
} 


\begin{tabular}{|c|c|c|}
\hline$A \tilde{n} o$ & $N^{o}$ total de documentos & $\begin{array}{l}N^{o} \text { en que se } \\
\text { nombra el } \\
\text { escriba }\end{array}$ \\
\hline $1217^{*}$ & 12 (números 1-12) & 8 docs. \\
\hline 1218 & $41(13-53)$ & 29 \\
\hline 1219 & $45(54-98)$ & 28 \\
\hline 1220 & $27(99-124,849)$ & 18 \\
\hline 1221 & $23(125-147)$ & 14 \\
\hline 1222 & $22(148-169)$ & 16 \\
\hline 1223 & $24(170-191,850,851)$ & 16 \\
\hline 1224 & $9(192-200)$ & 5 \\
\hline 1225 & $8(201-208)$ & 5 \\
\hline 1226 & $12(209-220)$ & 5 \\
\hline 1227 & $8(221-228)$ & 2 \\
\hline 1228 & $16(229-243)$ & 4 \\
\hline 1229 & $16(244-259)$ & 9 \\
\hline 1230 & $18(260-277)$ & 5 \\
\hline 1231 & $104(278-381)$ & 33 \\
\hline 1232 & $113(382-494)$ & 42 \\
\hline 1233 & $14(495-508)$ & 1 \\
\hline 1234 & $35(509-543)$ & 3 \\
\hline 1235 & $23(544-566)$ & 1 \\
\hline 1236 & $15(567-581)$ & 1 \\
\hline 1237 & $33(34 ?, 582-614,852 ?)$ & 2 \\
\hline 1238 & $29(615-643)$ & 3 \\
\hline 1239 & $20(644-663)$ & 7 \\
\hline 1240 & $3(664-666)$ & 0 \\
\hline 1241 & $22(667-688)$ & 3 \\
\hline 1242 & $16(689-704)$ & 0 \\
\hline 1243 & $15(705-719)$ & 2 \\
\hline 1244 & $4(720-723)$ & 0 \\
\hline 1245 & $8(724-731)$ & 0 \\
\hline
\end{tabular}

situación no sorprendente dada la pérdida de registros cancillerescos en Castilla durante la Edad Media. El número total de documentos expedidos sin duda variaba algo de un año a otro. A pesar de esto, del examen de la tabla a continuación pueden sacarse algunas inferencias provisionales. 


$\begin{array}{lccc}1246 & 14(732-745) & 0 & 0 \\ 1247 & 5(746-750) & 0 & 0 \\ 1248 & 21(751-771) & 5 & 24 \\ 1249 & 14(772-785) & 2 & 14 \\ 1250 & 26(786-811) & 20 & 77 \\ 1251 & 23(812-834) & 22 & 96 \\ 1252^{* *} & 14(835-848) & 12 & 86\end{array}$

*Seis últimos meses.

${ }^{* *}$ Cinco primeros meses.

Se hace patente que durante el largo oficio de Juan Díaz la proporción de documentos que contenían el nombre del escriba decreció desde más de $50 \%$ cada año en el período 1217-1225 hasta entre 25 y $50 \%$ durante los años 1226-1232 (menos en 1229 cuando era 56\%), menos de $10 \%$ durante los años 1233-1238, y, por fin, en una evolución desigual durante los últimos años del obispo (35\% en $1239,14 \%$ en $1241,13 \%$ en 1243 y $0 \%$ en $1240,1242,1244-1246)$. El interregno de 1247 dio poco fruto en su escaso número de documentos, todos sin nombre del escriba; la situación se parecía a la de los últimos tres años bajo Juan Díaz. Los datos para 1248 puede o no reflejar la influencia de Pedro Martínez porque no se sabe exactamente cuando llegó a ser vicecanciller. Ocupaba el oficio en 1249, sin embargo, cuando la identidad del copista se incluía en un porcentaje relativamente bajo de los documentos expedidos. Marcados cambios acompañan la llegada de Ramón de Losana a la notaría mayor, desde cuando la constancia en la notación de la identidad del escribano se mantenía entre $77 \%$ y $96 \%$. Ésta fue también la época en que se fijaron las fórmulas de identificación del personal cancilleresco en los privilegios rodados y otras cartas y cuando al mismo tiempo se estableció la clara diferencia entre estas fórmulas. El privilegio rodado del 20 de abril de 1250 (GoNZÁLEZ, Fernando III, número 788), por ejemplo, reza "Iohannes Petri Segobiensis scripsit de mandato domini Segobiensis episcopi magistri R., domini regis notarii". En otros tipos de las cartas reales sólo se anota el nombre del escriba más el verbo scripsit, una práctica en realidad comenzada después de febrero de 1249 (número 784, 24 de agosto) y por eso coincidente con el oficio del obispo Pedro. No obstante, las cifras aquí y sobre otras prácticas observadas muestran que la madurez de la política mencionada se realizaba solamente durante el oficio notarial del obispo Ramón. 
Es significativo que los escribas sorianos fueran responsables de cuarenta y seis documentos en latín y sólo cuatro en castellano mientras que los segovianos fueran responsables de treinta y ocho en latín pero treinta y uno en castellano. Además, de estos treinta y ocho en latín se atribuyeron treinta y uno a un solo escriba, Domingo, quien trabajó en la cancillería desde el principio del reinado (o antes) hasta 1230. De ahí la inferencia que mientras la castellanización de documentos en la cancillería real comenzó su aparición esporádica en 1223 (seis años después de que Fernando III subiera al trono) y cogió velocidad cuando el asedio de Jaén en 1246, se aceleró desde el tiempo del vicecanciller Pedro en 1249 y, notablemente, con la llegada a la cancillería del Maestro Ramón. En esta última época el grupo de escribas segovianos más otros cuyos nombres aparecen en los documentos cancillerescos aumentaban considerablemente el número del personal empleado para ejecutar los mandados del rey. El talento y el ejercicio del Maestro Ramón contribuían a su reorganización de la cancillería, especialmente de acuerdo con las disposiciones incluidas en la legislación alfonsina en cuya preparación el Maestro desempeñó un papel importante al formular normas nuevas y al modificar prácticas existentes.

\subsection{MOTIVOS PARA SUSTITUIR EL LATÍN}

Por qué el cambio de lenguas ocurrió en su época debe examinarse a la luz de al menos tres situaciones significativas: procesos y transformaciones, amplios y paulatinos, ya en marcha $(\S 1)$; la influencia ejercida por personajes cuya responsabilidad, formación superior y experiencia importante respondían bien a las necesidades de su tiempo y de su oficio $(\S 3)$; y un mayor reconocimiento consciente de distinciones entre lenguas. Al tratar la primera de estas situaciones, el movimiento hacia la vulgarización, pueden agregarse dos elementos no lingüísticos: conquistas militares y el crecimiento en heterogeneidad de la población dentro del reino. Desde el tiempo de la victoria que ganaron los cristianos en Las Navas de Tolosa (1212) y la trascendencia de ella al marcar el brusco viraje en el equilibrio de poder en la Península a favor de los cristianos frente a los musulmanes, un número creciente de participantes en los esfuerzos capitaneados por los reyes castellanos Alfonso VIII y Fernando III acudían de tierras ultrapirenaicas en 
adición a los que llegaban de varias partes de la Península misma ${ }^{22}$. Comunidades nuevas, estuvieran dentro o fuera de villas o pueblos existentes, algunas veces fueron pobladas por combatientes victoriosos y otras veces por inmigrantes de otras regiones de Castilla o del extranjero, reuniendo así gentes de diversos orígenes geográficos y quienes podían ser, y a veces eran, de una posición social o creencia religiosa diferentes ${ }^{23}$. La resultante heterogeneidad de la población en general (cualquiera que fuese la homogeneidad de los habitantes en una sola comunidad urbana) acrecentaba las modificaciones demográficas en marcha debidas al tráfico cada vez mayor a lo largo de las rutas jacobeas y a la corriente adjunta de inmigrantes evidente en los siglos XI, XII y XIII. Después que los castellanos habían sufrido la amarga derrota de Alarcos (1195), sus reacciones mental y física afirmativas que culminaron en la gran victoria en Las Navas contribuían además a aumentar las renovaciones comercial y cultural comenzadas aún antes $^{24}$. El fluctuar demográfico y el contacto creciente entre castellanos de regiones diferentes, entre castellanos y extranjeros y entre cualquier de aquéllos y musulmanes o judíos crecían en importancia la conveniencia de una lengua común. La forma escrita del habla fue cada vez más el romance en lugar del latín, hebreo o árabe, relacionada cada una de las tres a un dogma religioso diferente. Ninguna de estas lenguas fue adoptada como su habla normal por un gran número de los creyentes en otra fe. Por contraste,

\footnotetext{
${ }^{22}$ Rodericus XIMENIUS DE RADA, De rebus Hispaniae, libro VIII, capítulos V-XII, en PP Toletanorum, Opera, III (Madrid, 1793; reimpresión facsímil, Valencia, 1968). Se amplía la versión en la Estoria de Espanna (Primera Crónica General de España, ed. R. MENÉNDEZ PIDAL, Madrid, 1906, $3^{\mathrm{a}}$ ed. 1977), capítulos 1011-1022.

${ }^{23} \mathrm{La}$ variedad en los lugares de origen se hace patente cuando uno examina los nombres de los que recibían tierras según los libros de reparto redactados después que los cristianos conquistaron y repartieron ciudades y territorios musulmanes. Véanse especialmente Julio GONZÁLEZ, Repartimiento de Sevilla, 2 vols., Madrid, 1951, y, para una bibliografía reciente de ediciones modernas de tales libros, Manuel GONZÁLEZ JIMÉNEZ, Repartimientos andaluces del siglo XIII[.] Perspectiva de conjunto y problemas, "De Al-Andalus a la sociedad feudal: los repartimientos bajomedievales", Barcelona, 1990, pp. 95-117. Cf. Salvador DE MOxÓ, Repoblación y sociedad en la España cristiana medieval, Madrid, 1979, especialmente capítulos III y VIII

${ }^{24}$ Se remonta la renovación a no más tarde de los últimos dos decenios del siglo XI cuando se introducía en Castilla la liturgia romana, cuando la antigua capital del reino visigótico de Toledo cayó en manos de los cristianos y cuando tenía lugar la primera cruzada para liberar la Tierra Santa. La importancia que ejercían estos eventos en las comunicaciones, el comercio y la cultura es extensa y será bastante conocida para no necesitar elaboración dentro de los confines de este artículo.
} 
todos podían aceptar el romance más por voluntad propia como un medio general de comunicación, en la escritura tanto como en el habla. ${ }^{25}$

\subsection{UTILIDAD DE LA LENGUA VERNÁCULA}

Además de la utilidad proporcionada por una lengua común a todos los súbditos del rey fue la necesidad sentida de la lengua que en su forma escrita relacionaría la ampliada administración real más directamente con la gente. Lomax, en un ejemplo con respecto a portazgos, nos suministra una explicación sensata de la aparición en romance de documentos oficiales que respondían a tal necesidad: "Lo que tienen en común estas cartas y otras escritas en romance en los primeros años del reinado de San Fernando, es que por razón de su contenido, habían de ser examinadas muchísimas veces por portazgueros y alcaldes de pocos conocimientos lingüísticos en puertos de montaña o sitios apartados donde no se podía contar siempre con alguien que supiere el latín. ... Así, se empleaba el vernáculo en documentos que consultarían con frecuencia gente poco letrada, y también en documentos que contenían definiciones legales, topográficas y jurisdiccionales que requerían amplia publicidad"26. Concurrían varias circunstancias - la expansión territorial del reino, una administración más amplia, modificaciones demográficas y una tradición oral con su frecuente uso en pleitos de la lengua vernácula - para contribuir, de una manera o de otra, a aumentar el número del personal cancilleresco y su uso mayor del vernáculo ${ }^{27}$. Por cierto, en la época alfonsina el romance llegó a significar la elección del castellano (incluyendo sus variedades) u otros dialectos vernáculos - los que Amado Alonso llamaba "determinaciones especiales del nombre común

\footnotetext{
${ }^{25}$ MacDonald, edición del Espéculo, capítulo 19.1-.3, y edición del Libro de las tahurerías, capítulo 13.5 .

${ }^{26}$ Lomax, La lengua oficial, pp. 413-415 (cita de la p. 413).

${ }^{27} \mathrm{Cf}$. Brian DutTon, The Popularization of Legal Formulae in Medieval Spanish Literature, "Medieval, Renaissance and Folklore Studies in honor of John Esten Keller", ed. Joseph R. JONES, Newark (Delaware), 1980, artículo citado en mi comentario (capítulo 18.24.c de la introducción) sobre fórmulas no legales en el Libro de las tahurerías. Véase también LOMAX, La lengua oficial, p. 414. En el Espéculo alfonsino, V.13.7.c, se permitía que la decisión judicial pudiera ser leída por un sustituto designado "ssi el [juez] non ssopiere leer". Uno infiere que se usaba la lengua vernácula en tales deliberaciones y que se anunciaba el juicio en la misma lengua para que todas las partes pudieran entenderlo.
} 
'romance'"28 - y no solamente el predominio de uno de ellos elevado arbitrariamente a una posición superior. La idea del 'castellano derecho' podría haberse referido a una forma de la lengua conocida en la Corte o cuyo uso en la escritura fomentaba el rey, pero el testimonio abundante de documentos legislativos y de las obras literarias confeccionadas y publicadas bajo el mandato de Alfonso X subraya el enfoque pragmático de este rey, de los especialistas de su escritorio y de los clérigos de su cancillería al escoger la forma escrita del habla que parecía más apropiada en una situación particular o para destinatarios específicos ${ }^{29}$. La actitud tenía su origen en la cancillería fernandina una vez que el romance empezaba a ocupar el lugar del latín y donde el uso de cierta lengua vernácula respondía menos a un juicio real (que habría manifestado una base ideológica) y más a las habilidades y a la educación del nuevo personal y, especialmente, a lo apropiado de la lengua o del dialecto escogido para su aplicación según la circunstancia.

\footnotetext{
${ }^{28}$ Amado Alonso, Castellano, español, idioma nacional, Buenos Aires, $3^{\text {a }}$ edición, 1958, p. 12 .

${ }^{29}$ Rafael LAPESA en su Historia de la lengua española, Madrid, 9a ed., 1981, $\S \S 47$ y 63.3, identifica variaciones regionales del castellano y comenta aspectos del "castellano drecho". (La forma "drecho" fue identificada por R. Menéndez Pidal como un aragonesismo. En De Alfonso [X] a los dos Juanes[.] Auge y culminación del didacticismo (1252-1370), artículo redactado a principios de 1940 y publicado póstumamente por Diego CATALÁN en "Studia hispanica in honorem R. Lapesa" [3 vols., Madrid, 1972-1975], I, pp. 63-83). Ramón MENÉNDEZ PIDAL trata dialectismos encontrados en obras alfonsinas (ob. cit., pp. 72-74). Noté la aparición de ciertos dialectos y dialectismos en documentos de la cancillería alfonsina en mi edición del Espéculo, capítulo 19.7-.8, y en la de las Tahurerías, capítulo 13.5. Un repaso rápido de diplomas expedidos por la cancillería fernandina después de 1240 revela que el castellano es la lengua en la mayoría de los originales y copias aunque en los números 795 (copista sin nombrar), 797 y 799 (escritos por Juan Pérez de Berlanga) y 801 (escrito por Sancho), ningún diploma es el original y se dirigen todos a destinatarios en Santiago de Compostela. En los cuatro documentos referidos se hallan características ortográficas del oeste hispánico, por ejemplo, en aquela, daquelos; dom; leixen; maneyra, primeyro; outorgo; pierdam, uenierem; preyto, prazer; sem; senpre, tenpo, terra (cf. LoMAX, La lengua oficial, p. 416). La uniformidad relativa en el uso del castellano y en el castellano escogido puede atribuirse a varios factores entre los cuales predomina "el destino" primariamente castellano de los documentos y "el origen" castellano (principalmente de Soria o de Segovia) de escribas y de los vicecancilleres Juan y Pedro y del notario mayor Ramón. No se sabe si las comunicaciones dirigidas a Castilla después de 1230 fueron en verdad de mayor número que las para otras tierras del reino donde predominaban otros dialectos porque uno no puede estar seguro de qué porcentaje de la producción total de documentos cancillerescos se ha recobrado. En mi edición sobre las Tahurerías, capítulos 13 y 1.9, ya presté atención al pragmatismo lingüístico de Alfonso X y sus estudiosos.
} 


\subsection{EL USO CRECIENTE DEL ROMANCE EN DOCUMENTOS REALES Y NO REALES}

C. Hernández encuentra el uso del castellano en "casi todos" los documentos no reales en Palencia desde $1222^{30}$. Por contraste, González escribe que la cancillería real expidió su primera carta en lengua vernácula en 1223, con otras instancias encontradas sólo esporádicamente años después. Así que, al menos en una región, la literatura documental no real en que se usaba el romance generalmente antecedía por algunos años una preferencia semejante establecida en la cancillería del rey, aunque en ambos casos el período de transición se fija hacia finales del primer cuarto del siglo $^{31}$. En la primera mitad del siglo XIII el número de ejemplos y la importancia de la literatura no documental en castellano - si original, si evolucionaba o si era una traducción - crecían notablemente en formas como el poema épico (por ejemplo, la versión del Poema de mio Cid conocida en aquel entonces), el poema lírico (canciones) y narraciones (por ejemplo, la Fazienda de Ultramar). Aun cuando se decía que el desarrollo de una lengua literaria todavía quedaba gradual e incompleto en la época de Gonzalo de Berceo (también la generación de Fernando III), el castellano seguía un curso hacia la generalización, a expensas de dialectos vecinos, como la "lengua poética" del centro de la Península ${ }^{32}$. Por cierto, el uso del castellano manifestaba una percepción creciente de la lengua popular como un vehículo

\footnotetext{
${ }^{30}$ César Hernández, Acercamiento al castellano, p. 332. Unos pocos ejemploss prefernandinos del romance como la lengua predominante en documentos reales $y$, además, un diploma esporádico expedido por la cancillería real de Castilla entre 1191 y 1210 , durante el reinado de Alfonso VIII, fueron objeto de atención por Roger WRIGHT en Latin and Romance. pp. 115-128. Documentos no reales en castellano vuelven a aparecer en 1221 (Wright, citando a Menéndez Pidal). MenÉndez PIDAl, en el Prefacio de Orígenes del español, $6^{a}$ ed., 1968, p. IX, colocó una segunda y perdurable corriente de romancear la lengua en documentos notariales durante el último tercio del siglo XII, una época cercana a "la época literaria, conocida ya en manuscritos auténticos desde poco antes de 1200".

${ }^{31}$ En un estudio anterior que suponía el uso del latín o de la lengua vernácula en documentos (todos aparentement no reales) relacionados con el monasterio de Osera (bajo el mandato fernandino sólo desde 1230), Manuel LUCAS FERNÁNDEZ, Documentos notariales y notarios en el monasterio de Osera, en "Actas de las I Jornadas de Metodología Aplicada de las Ciencias Históricas", Santiago, 1975, V, pp. 223-240, halló que los primeros documentos en gallego habían aparecido junto con el número mayor en latín en los años comprendidos entre el 1266 y el 1300, inclusive, y el uso exclusivo del gallego desde el 1301. El año 1266 Lucas lo asocia con la influencia de la legislación alfonsina y, específicamente, con las Siete Partidas cuya redacción se había completado poco antes.
}

${ }^{32}$ LaPESA, Historia, § 52. Cf. MenÉndez Pidal, De Alfonso, p. 63. 
de comunicaciones escritas efectivo y respetable y por eso competitivo con la lengua preferida por los latinistas ${ }^{33}$. Durante el reinado de Alfonso $\mathrm{X}$ el castellano (incluyendo variedades regionales) se hizo el medio general empleado en mucha prosa secular mientras en la Corte y sobre todo en la administración real su uso era la norma. El latín y el romance castellano fueron reconocidos expresamente como dos lenguas diferentes, cada una con su propio nombre y carácter $)^{34}$. Puede encontrarse la distinción consciente en una fecha prealfonsina?

\subsection{COMENTARIO FINAL}

Aunque diferían las situaciones en cuanto a la fase del desarrollo o del grado de madurez en la lengua vernácula, el uso en siglos anteriores de glosas léxicas para suministrar otras acepciones mejor conocidas al lector indica un grado de conciencia lingüística de parte de los glosistas, aun cuando queda la pregunta respecto al punto si esta conciencia mostraba sencillamente una identificación de variación en lenguaje más bien que una distinción deliberada hecha entre lenguas ya vistas como independientes ${ }^{35}$. La práctica en la cancillería fernandina muestra cierta integración en el uso del latín (en oraciones introductorias y finales de los diplomas) y del

\footnotetext{
${ }^{33}$ Roger WRIGHT, Escribir el Poema de mio Cid, en " 'Al que en buen hora nasçio'[.] Essays on the Spanish Epic and Ballad in Honour of Colin Smith", eds. Brian POWELL y Geoffrey WEST, Liverpool University Press, 1996, p. 189 (cf. p. 198), fija los años 1206 (Tratado de Cabreros) y 1207 (Poema de mio Cid) como aquellos en los que se señalaba "un reconocimiento oficial de la existencia de dos niveles de lengua escrita; desde ca. 1220 se puede decir, de cada sección de cada documento oficial, que se escribió o bien en latín o bien en romance, descartada la hibridación prevalente del siglo anterior". LAPESA, Historia, § 47.6, atestigua que la influencia latinista de los escribas contribuía a ocultar características romances durante los siglos XI y XII.

${ }^{34} \mathrm{~A}$ [ntonio] G[ARCíA] SOLALINDE, La expresión 'nuestro latín' en la "General Estoria" de Alfonso el Sabio, "Homenatge a Antoni Rubió i Lluch: Miscellánia d'Estudis literaris històrics i lingüístics" (3 vols., Barcelona, 1936), I, pp. 133-140, y R. MENÉNDEZ PIDAL, De Alfonso, pp. 74-75. El estudio de Solalinde demuestra que en la situación no faltaban ni complejidades ni sutilezas.

${ }^{35}$ "No obstante la introducción y divulgación de las litterae al final del siglo XI, la oposición entre latín y romance como códigos distintos dotados de escrituras distintas sólo se estableció duraderamente cerca de dos siglos después, como consecuencia de un proceso dilatado de cambio metalingüístico que instauró la noción de que el latín y las lenguas vernáculas hispánicas eran objetivamente cosas distintas". Antonio EmILIANO, Latín y romance y las glosas de San Millán y de Silos: apuntes para un planteamiento grafémico, "Actas del Primer Congreso Anglo-Hispano" (2 vols., Madrid, 1993), I, pp. 235-244 (cita de p. 235).
} 
romance (en el cuerpo o sustancia del mensaje) al mismo tiempo que estas lenguas iban reconocidas como distintas. La prueba de esto está en el mandado del rey sobre la traducción del Fuero de Toledo cuando Fernando III se lo otorgó a Córdoba (véase la nota 13). Uno concluiría, pues, que el año 1241 sirve no solamente del terminus ad quem más avanzado del reconocimiento real y cancilleresco de lenguas diferentes, sino también como un terminus a quo del uso general del romance en la cancillería. El cambio -el abandono del latín y el empleo del romance- era una elección intencionada basada en más que sólo la conciencia de lenguaje diferente. Tal conclusión es confirmada en el curso de los años 1240 por el crecimiento rápido en el empleo del romance en la redacción de documentos cancillerescos. He notado que un terminus ad quem anterior, 1206/1207 en el reinado de Alfonso VIII, fue establecido por Wright para señalar el reconocimiento de la diferenciación entre lenguas ${ }^{36}$ aunque, como muestran las pruebas, esto entonces no señalaba la utilización general del romance en diplomas emanados de la cancillería. Quizá algunos piensan que las dos ocasiones apuntadas por Wright representan eventos relativamente aislados. Pero también estas importantes instancias concurrentes del romance en la legislación y en la literatura pueden verse - y yo creo con razón- como sintomáticas de un movimiento ya comenzado, aunque en la escritura específicamente cancilleresca el romance castellano se pondría de manifiesto solamente de vez en cuando durante una generación más.

\section{RÉSUMÉ}

En Castille le mouvement de vernacularisation s'est manifesté en loi, en littérature, et en historiographie au cours du treizième siècle. Dans la chancellerie royale, ce changement s'est produit pendant le deuxième quart du siècle. Les agents principaux en

\footnotetext{
${ }^{36}$ En la nota 33. MEnÉndez PIDAL, Orígenes, Prefacio, p. VIII, se refería a una corriente inicial de formas en romance en el periodo comprendido desde el siglo IX hasta el último tercio del siglo XI, pero, como en el caso de las glosas mencionadas antes, en aquel momento este hecho significaba menos el reconocimiento de lenguas distintas que la conciencia de variaciones en el lenguaje. La corriente resultó prematura cuando la influencia de latinistas estableció, de nuevo, la primacía del latín la cual duró un siglo más. Aún en el siglo XII, en la Chronica Adefonsi Imperatoris, ed. Luis SÁNCHEZ BELDA, Madrid, 1950, \110, la diferenciación hecha entre el latín en que se escribía el poema y la mención de la preferencia contemporánea - "miserunt insidias, quas lingua nostra dicunt celatas" - meramente demuestra una elección léxica en la escritura que podría o no haber reflejado el uso preferido en el habla.
} 
étaient les vice-chanceliers et certains scribes, surtout ceux de Ségovie. La langue romane écrite y était reconnue comme une langue séparée du latin, plutôt qu'une déformation ou qu'une variation, dès la première décade du treizième siècle. Son emploi était généralisé après le milieu des années 1240 dans une opération accomplie avant le milieu du siècle.

\section{SUMMARY}

In Castile the movement in favor of vernacularization became manifest in law, literature, and historiography during the thirteenth century. In the royal chancery the change occurred during the second quarter of the century. The principal agents were the vicechancellors and certain scribes, notably those from Segovia. Written Romance was first recognized as a language separate from Latin, rather than as a deformation or variety of it, no later than the first decade of the thirteenth century. Its use was generalized in the chancery after the middle of the 1240 s in a process completed by mid-century. 